Article

\title{
Luminescent Properties of Lanthanoid-Poly(Sodium Acrylate) Composites: Insights on the Interaction Mechanism
}

\author{
Alan F. Y. Matsushita ${ }^{1} \mathbb{D}$, María José Tapia ${ }^{2}$, Alberto A. C. C. Pais ${ }^{1}$ and Artur J. M. Valente ${ }^{1, * \mathbb{D}}$ \\ 1 CQC, Department of Chemistry, University of Coimbra, 3004-535 Coimbra, Portugal; \\ alanmatsushita@hotmail.com (A.F.Y.M.); pais@ci.uc.pt (A.A.C.C.P.) \\ 2 Department of Chemistry, Universidad de Burgos, 09001 Burgos, Spain; mjtapia@ubu.es \\ * Correspondence: avalente@ci.uc.pt; Tel.: +351-239-852-080
}

Received: 12 May 2020; Accepted: 4 June 2020; Published: 9 June 2020

\begin{abstract}
The interaction between polyelectrolytes and metal ions is governed by different types of interactions, leading to the formation of different phases, from liquid state to weak gels, through an appropriate choice of metal ion/polyelectrolyte molar ratio. We have found that lanthanide ions, europium(III) and terbium(III), are able to form polymer composites with poly(sodium acrylate). That interaction enhances the luminescent properties of europium(III) and terbium(III), showing that $\mathrm{Eu}^{3+} /$ poly(sodium acrylate) (PSA) and $\mathrm{Tb}^{3+} / \mathrm{PSA}$ composites have a highly intense red and green emission, respectively. The effect of cations with different valences on the luminescent properties of the polymer composites is analyzed. The presence of metal ions tends to quench the composite emission intensity and the quenching process depends on the cation, with copper(II) being by far the most efficient quencher. The interaction mechanism between lanthanoid ions and PSA is also discussed. The composites and their interactions with a wide range of cations and anions are fully characterized through stationary and non-stationary fluorescence, high resolution scanning electronic microscopy and X-ray diffraction.
\end{abstract}

Keywords: fluorescence quenching; polymer composite; lanthanoid complex; metal-organic gel; responsive gel

\section{Introduction}

Metal-organic materials have received great attention in recent years, because of the metal-ligand interaction, which can form three-dimensional structures, such as metal-organic frameworks (MOF) and metal-organic gels (MOG); these materials have already presented promising applications for supercapacitors, sensing, catalysis and optoelectronics [1-5]. MOG preparation is simpler, involving hydrogen bonding interactions, $\pi-\pi$ stacking, van der Waals forces and coordination bonds under mild conditions to form self-assembled supramolecular structures [6,7]. On the other hand, MOF usually display a highly crystalline structure, therefore requiring a more time-consuming preparation [8]. MOG, on the contrary, are characterized by extended structures, essentially driven by metal-ligand interactions, where the polymer (ligand) acts as a gelling agent [9]. These materials may show selective sensing to different stimuli including cations and anions $[6,10]$. Some advantages of these MOGs include high sensitivity, availability, fast response to a stimulus, low cost (small amounts of probe is required) and fluorescence, which is a technique frequently used in the sensing field [11]. In this regard, lanthanoid complexes have interesting spectroscopic properties-such as large Stokes shift, narrow emission bands, long emission lifetimes and high emission quantum yields [12] — being a good alternative as sensors for detection of cations, anions and biomolecules. In fact, the detection of metals, 
such as copper(II) — a relevant ion for biochemical and environmental issues [13-15]—can be done by different methods, including electrochemical methods, UV-vis spectroscopy, atomic absorption, inductively coupled plasma and atomic emission spectrometry (ICP-AES) [16-19]. These methods generally require costly equipment and the specific preparation of samples. Hence, the development of fluorescent sensors for metal ions has increased in recent years [20-23].

Following our previous work [24], we describe here the synthesis and characterization of two new polymer composites consisting of lanthanoid metal ions (europium and terbium) and a polyelectrolyte. The luminescent properties of these compounds were assessed, making it possible to have an insight into the mechanism of interactions between lanthanoid ion and the polyelectrolyte. Additionally, the effect of cations with different stable valences and good solubility were assessed to better understand the hypothetical competition mechanism with lanthanoid ions on the poly (sodium acrylate)- $\mathrm{Ln}^{3+}$ interaction; moreover, and once that salts with different monovalent anions were used, a series of monovalent anions were also studied. That made it possible to shed light on the possible application of these matrices for sensing, remediation or anti-counterfeiting.

\section{Materials and Methods}

\subsection{Reagents}

All chemicals were commercially available and used without further purification. The following salts: europium(III) chloride hexahydrate, terbium(III) chloride hexahydrate, aluminum hydroxide hydrate, calcium chloride dihydrate, cerium(III) chloride heptahydrate, chromium(III) chloride hexahydrate, copper(II) chloride dihydrate, mercury(II) thiocyanate, potassium chloride, sodium chloride, sodium acetate, sodium bromide, sodium cyanide, sodium fluoride, nickel nitrate hexahydrate, lead(II) nitrate, zinc chloride and poly(sodium acrylate) (PSA, $\overline{M_{w}}=2100 \mathrm{~g} \mathrm{~mol}^{-1}$ ) were purchased from Sigma-Aldrich (Steinheim, Germany). Sodium acetate, magnesium nitrate hexahydrate, were obtained from Fluka (Gillingham, UK) and anhydrous aluminum chloride, sodium nitrite and potassium thiocyanate were purchased from Merck (Darmstadt, Germany). Milli-Q water was used in all the experiments.

\section{2. $\mathrm{Eu}^{3+} / \mathrm{PSA}$ and $\mathrm{Tb}^{3+} / \mathrm{PSA}$ Composite Solutions}

The $\mathrm{Eu}^{3+} / \mathrm{PSA}$ and $\mathrm{Tb}^{3+} / \mathrm{PSA}$ composites were prepared by dissolving PSA $\left(0.26 \mathrm{~mol} \mathrm{dm}^{-3}\right.$, in terms of polymer repetition units, whose repetitive unit molecular weight is $108.08 \mathrm{~g} \mathrm{~mol}^{-1}$ ) in milli-Q water, and the subsequent dropwise addition of europium or terbium chloride hexahydrates $\left(0.026 \mathrm{~mol} \mathrm{dm}^{-3}\right)$, under continuous magnetic stirring. The same method was used elsewhere [24]. The $\mathrm{pH}$ of the solutions was adjusted at around 7.5, by adding either $\mathrm{NaOH}$ or $\mathrm{HCl}\left(0.1 \mathrm{~mol} \mathrm{dm}^{-3}\right)$, due the $\mathrm{pK}$ a value of PSA and the solubility of $\mathrm{Eu}^{3+}$ and $\mathrm{Tb}^{3+}$ [25]. It has been found that the addition of salts did not change the solution $\mathrm{pH}$. Additionally, the stability of solutions was verified spectrophotometrically for at least 2 weeks after preparation [24].

\subsection{Preparation of Metal-Organic Gels}

Freshly prepared solutions of $\mathrm{Eu}^{3+} / \mathrm{PSA}$ and $\mathrm{Tb}^{3+} / \mathrm{PSA}$ were used for the luminescent studies. To investigate the selectivity of the composites towards different metal ions, aliquots of metallic ion stock solutions $\left(\mathrm{Al}^{3+}, \mathrm{Ca}^{2+}, \mathrm{Ce}^{3+}, \mathrm{Cr}^{3+}, \mathrm{Cu}^{2+}, \mathrm{Hg}^{2+}, \mathrm{K}^{+}, \mathrm{Mg}^{2+}, \mathrm{Na}^{+}, \mathrm{Ni}^{2+}, \mathrm{Pb}^{2+}\right.$ and $\mathrm{Zn}^{2+}$ ) were added to $\mathrm{Eu}^{3+} / \mathrm{PSA}$ and/or $\mathrm{Tb}^{3+} / \mathrm{PSA}$ solution. The final concentration of metal ions in the solution was fixed at $3.33 \mathrm{mM}$. The solution was mixed using an ultrasonic bath for $30 \mathrm{~min}$, before the emission spectra was recorded. All the spectra were registered at $25^{\circ} \mathrm{C}$.

\subsection{Apparatus and Characterization Methods of Eu(III)/PSA and Tb(III)/PSA}

The UV-vis spectra of solutions were recorded on a Shimadzu 2450 UV-vis spectrophotometer (Kyoto, Japan). 
Emission spectra were recorded with a Fluoromax-4 spectrofluorometer (Kyoto, Japan), in a right-angle configuration, with excitation at $395 \mathrm{~nm}\left(\mathrm{Eu}^{3+}\right)$ and $273 \mathrm{~nm}\left(\right.$ for $\left.\mathrm{Tb}^{3+}\right)$, and emission spectra scanned between 550 and $750 \mathrm{~nm}$ and 450 and $650 \mathrm{~nm}$, respectively. Excitation and emission slits of 0.5 and $1.0 \mathrm{~nm}$, respectively, were used.

$\mathrm{Tb}^{3+}$ and $\mathrm{Eu}^{3+}$ luminescence lifetimes were measured with the multi-channel scaling mode (MCS) counter module (TCC2) of the FLS980 spectrometer (Edinburgh Instruments, Livingston, UK), using a microsecond flash Xe-lamp $(\mu \mathrm{F} 2)$ as light source. The decays were registered by exciting the composites at $395 \mathrm{~nm}$ and $270 \mathrm{~nm}$ and recording the emission at $613 \mathrm{~nm}$ and $543 \mathrm{~nm}$ for $\mathrm{Eu}^{3+} / \mathrm{PSA}$ and $\mathrm{Tb}^{3+} / \mathrm{PSA}$, respectively. The decays were analyzed with the software of the equipment.

High Resolution Scanning Electronic Microscopy (HR-SEM) micrographs were obtained using a ZEISS Merlin scanning electron microscope (Oerzen, Germany), operating under low vacuum at $2 \mathrm{kV}$. Elemental analysis on microscopic sections of composites was performed by Energy Dispersive Spectroscopy-Oxford Instruments, Oxon, UK. The samples used in these techniques were previously frozen at $-20^{\circ} \mathrm{C}$ and then lyophilized (Free Zone 4.5-Labconco), before being sputter-coated with a thin gold layer.

X-ray diffractograms were obtained with freeze-dried samples with the (X-ray Diffractometer Rigaku Ultima IV, Tokyo, Japan) with the following characteristics: $\mathrm{Cu}-\mathrm{k} \alpha$ radiation $(1.54 \mathrm{~A})$ in the range of $5^{\circ}$ to $120^{\circ}$ at a scan speed of $2 \theta / \mathrm{min}$.

\section{Results}

\subsection{Lanthanoid-PSA Interactions}

The $\mathrm{Eu}^{3+} / \mathrm{PSA}$ and $\mathrm{Tb}^{3+} / \mathrm{PSA}$ complexes, synthesized using a previous method [24], show an enhanced luminescence intensity in comparison to the free lanthanoides (see Figure 1). The metal-polymer interactions are likely due to the PSA carboxylic groups acting as chelators to the lanthanoid ions.
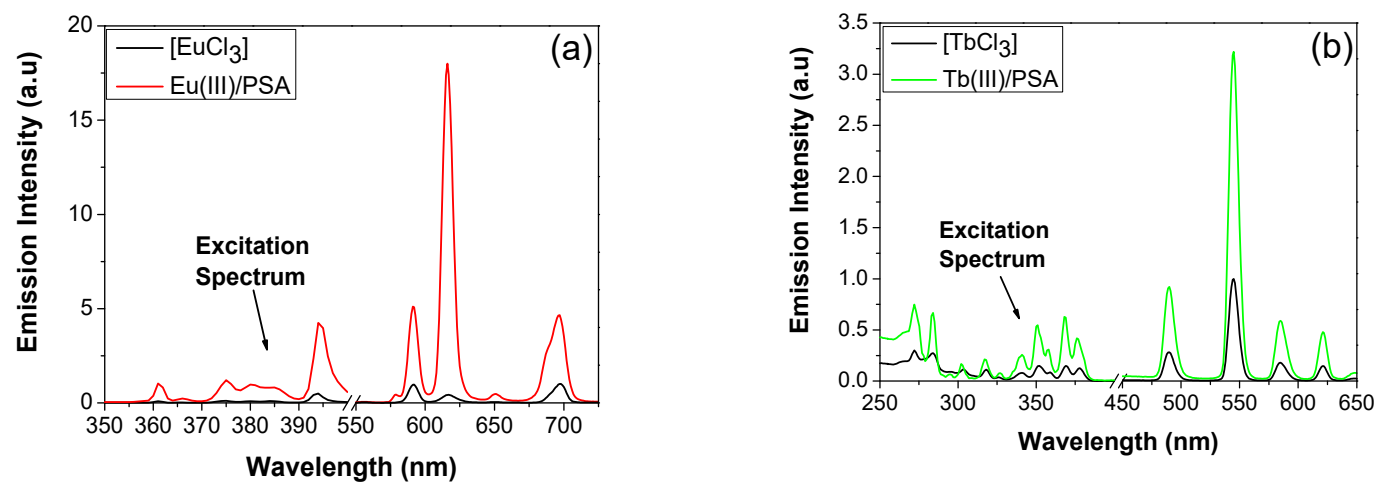

Figure 1. Excitation spectra (left side) and emission spectra (right side) of (a) $\mathrm{EuCl}_{3}$ and $\mathrm{Eu}^{3+} / \mathrm{PSA}$ $\left(\lambda_{\mathrm{em}}=616 \mathrm{~nm}\right.$ and $\left.\lambda_{\mathrm{ex}}=395 \mathrm{~nm}\right)$ and $(\mathbf{b}) \mathrm{TbCl}_{3}$ and $\mathrm{Tb}^{3+} / \mathrm{PSA}\left(\lambda_{\mathrm{em}}=545 \mathrm{~nm}\right.$ and $\left.\lambda_{\mathrm{ex}}=273 \mathrm{~nm}\right)$ in aqueous solutions at $\mathrm{pH} 7.2$.

From analysis of Figure 1, it can be observed that upon excitation at $395 \mathrm{~nm} \mathrm{Eu^{3+ } / P S A}$ exhibits strong emission peaks at 580,593, 616, 652 and $694 \mathrm{~nm}$. These peaks can be assigned to the characteristic ${ }^{5} D_{0} \rightarrow{ }^{7} F_{\mathrm{J}}(\mathrm{J}=0-4)$ transitions of the $\mathrm{Eu}^{3+}$ ion. The ${ }^{5} D_{0} \rightarrow{ }^{7} F_{1}$ transition is a magnetic dipole transition, which corresponds to the weak emission band at $593 \mathrm{~nm}$, less sensitive to the coordination environment. Therefore, when $\mathrm{Eu}^{3+}$ ions occupy the non-inversion centers sites, the electric dipole transition ${ }^{5} D_{0} \rightarrow{ }^{7} F_{2}$ is dominant promoting red-light emission. By comparing the transitions ${ }^{5} D_{0} \rightarrow{ }^{7} F_{2}$ and ${ }^{5} D_{0} \rightarrow{ }^{7} F_{1}$, we obtain an intensity ratio $I\left({ }^{5} D_{0} \rightarrow{ }^{7} F_{2}\right) / I\left({ }^{5} D_{0} \rightarrow{ }^{7} F_{1}\right)$ of about 3.4 , thus indicating that $\mathrm{Eu}^{3+}$ occupies non-inversion centers [26,27]. Similarly, upon excitation at $273 \mathrm{~nm}, \mathrm{~Tb}^{3+} / \mathrm{PSA}$ displays four clearly resolved peaks at 490, 545, 585 and $623 \mathrm{~nm}$, which can be ascribed to ${ }^{5} D_{4} \rightarrow{ }^{7} F_{\mathrm{J}}(J=6-3)$ transitions of $\mathrm{Tb}^{3+}$ ions. ${ }^{5} \mathrm{D}_{4} \rightarrow{ }^{7} F_{5}$ is an electric induced dipole transition, which is characterized by the 
intense emission band at $545 \mathrm{~nm}$, more sensitive to the coordination environment [28,29]. Additionally, the lanthanoid(III)-polymer interaction should lead to a concomitant dehydration of metal ions [30]. To have an assessment on such hypothesis, non-stationary fluorescence experiments were carried out, to allow the computation of the number of water molecules coordinating the lanthanoid; this can be done by comparing the fluorescence lifetime of $\mathrm{Tb}^{3+}$ and $\mathrm{Eu}^{3+}$ in aqueous and $\mathrm{D}_{2} \mathrm{O}$ solutions [30-32]. The decays of $\mathrm{Tb}^{3+}$ and $\mathrm{Eu}^{3+}\left(2.7 \times 10^{-2} \mathrm{~mol} \mathrm{dm}^{-3}\right)$ luminescence were registered in the absence and in the presence of PSA $\left(0.23 \mathrm{~mol} \mathrm{dm}^{-3}\right.$, in terms of monomer), both in $\mathrm{H}_{2} \mathrm{O}$ and $\mathrm{D}_{2} \mathrm{O}$ solutions. Good monoexponencial decays were observed in all the cases, from which lifetimes $(\tau)$ and decay constants ( $k$, reciprocal lifetime) were obtained (Table 1$)$. From this, the number of bound water molecules $(n)$ was computed. It has been found that $\mathrm{Eu}^{3+}$ and $\mathrm{Tb}^{3+}$, in aqueous solution, are coordinated by nine water molecules, which is in good agreement with the literature data [31]. However, in the presence of PSA, the number of bound water molecules decrease to approximately three. Such a decrease in the number of water coordinated molecules have also been observed for lanthanoids interacting with poly(vinyl sulfate) [33] or sodium dodecyl sulfate [34]. It can be concluded that PSA can replace up to six lanthanoid water coordinated molecules, indicating a strong interaction with $\mathrm{Ln}^{3+}$ ions, partially inhibiting the efficient radiationless lanthanoid emission deexcitation pathway via energy transfer to $\mathrm{OH}$ vibrational overtones [31,35]. This fact explains the significant increase of $\mathrm{Eu}^{3+}$ and $\mathrm{Tb}^{3+}$ emission intensity upon complexation with PSA (Figure 1).

Table 1. Lifetimes $(\tau)$, decay constant $(k)$ and number of coordinated water molecules $(n)$ of $\mathrm{Eu}^{3+}$ and $\mathrm{Tb}^{3+}$ in water and $\mathrm{D}_{2} \mathrm{O}$ and in poly(sodium acrylate) (PSA) aqueous and $\mathrm{D}_{2} \mathrm{O}$ solutions.

\begin{tabular}{ccccc}
\hline Sample & Solvent & $\boldsymbol{\tau}(\boldsymbol{\mu s})$ & $\boldsymbol{k}\left(\mathbf{m s}^{-\mathbf{1})}\right.$ & $\begin{array}{c}\boldsymbol{n} \\
\left(\mathbf{H}_{\mathbf{2}} \mathbf{O} \text { Coordinated }\right)\end{array}$ \\
\hline $\mathrm{EuCl}_{3}$ & $\mathrm{H}_{2} \mathrm{O}$ & 112 & 8.92 & 9 \\
$\mathrm{EuCl}$ & $\mathrm{D}_{2} \mathrm{O}$ & 1775 & 0.56 & 3 \\
$\mathrm{Eu}_{3}^{3+} / \mathrm{PSA}$ & $\mathrm{H}_{2} \mathrm{O}$ & 274 & 3.65 & \\
$\mathrm{Eu}^{3+} / \mathrm{PSA}$ & $\mathrm{D}_{2} \mathrm{O}$ & 1602 & 0.62 & 9 \\
$\mathrm{TbCl}_{3}$ & $\mathrm{H}_{2} \mathrm{O}$ & 431 & 2.32 & 3 \\
$\mathrm{TbCl}_{3}$ & $\mathrm{D}_{2} \mathrm{O}$ & 3565 & 0.28 & \\
$\mathrm{~Tb}^{3+} / \mathrm{PSA}$ & $\mathrm{H}_{2} \mathrm{O}$ & 861 & 1.16 & \\
$\mathrm{~Tb}^{3+} / \mathrm{PSA}$ & $\mathrm{D}_{2} \mathrm{O}$ & 3002 & 0.33 & \\
\hline
\end{tabular}

A further insight into the interaction mechanism can also be gained from the analysis of lanthanoid/PSA solid composite. The XRD patterns of PSA, and $\mathrm{Eu}^{3+}$ and $\mathrm{Tb}^{3+}$ composites are shown in Figure 2. In the PSA diffraction pattern, we can see only a large shoulder diffuse peak, showing the amorphous structure of the polymer [36]. Unlike this, $\mathrm{Eu}^{3+} / \mathrm{PSA}$ and $\mathrm{Tb}^{3+} / \mathrm{PSA}$ diffractograms show a series of diffraction peaks at $2 \theta=27.4,31.5,45.4,56.5,66.3,75.4$ and 83.9, and these peaks are assigned to the (111), (200), (220), (400), (420) and (422) plane of the NaCl-type structure [37]. This fact corroborates the occurrence of lanthanoid-PSA interaction, since the formation of $\mathrm{NaCl}$ is a consequence of the release and consequent interaction of counterions. It is also worth noting that no peak corresponding to the $\mathrm{EuCl}_{3}$ and $\mathrm{TbCl}_{3}$ crystal structure is observed, confirming that an interaction occurs, instead of a simple doping. 

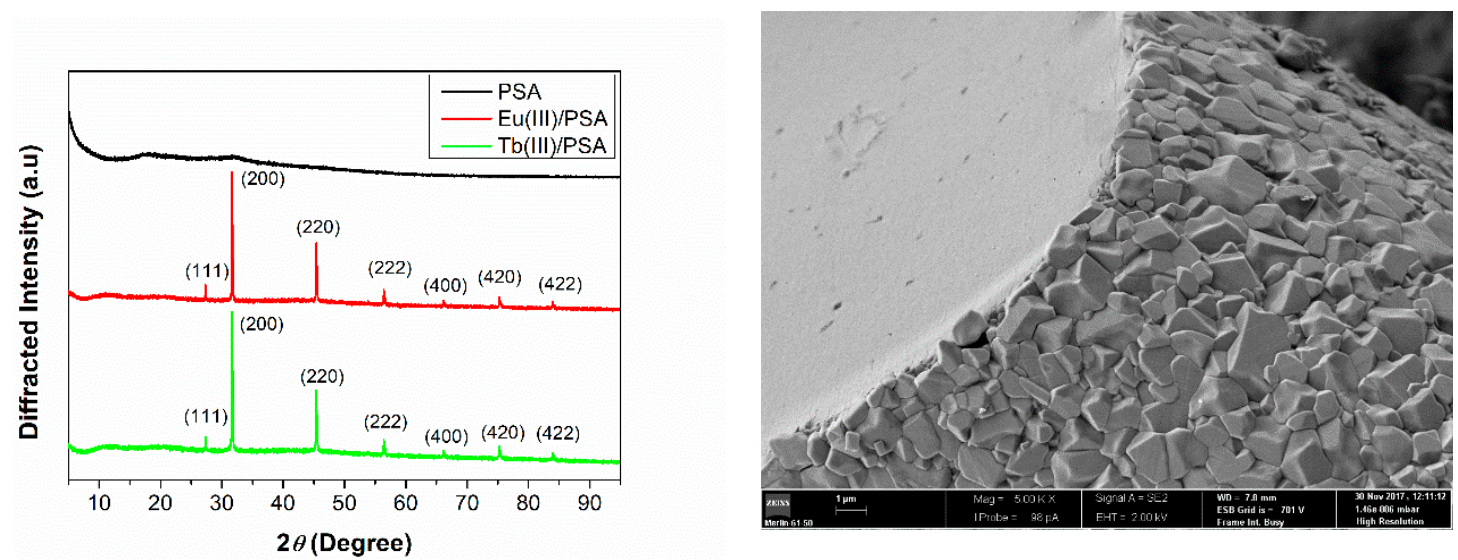

Figure 2. XRD patterns of PSA (black), Eu ${ }^{3+} / \mathrm{PSA}$ (red) and $\mathrm{Tb}^{3+} / \mathrm{PSA}$ (green), (left) and SEM micrograph of $\mathrm{Eu}^{3+} / \mathrm{PSA}$ freeze drying composite (right). Magnification 5000×.

The SEM micrograph (Figure 2, right side) shows that the composite is covered with crystals, but the cross-section has a different and featureless morphology suggesting a different composition. Finally, the elemental mapping and EDX spectra (Figure S1) of $\mathrm{Eu}^{3+} / \mathrm{PSA}$ and $\mathrm{Tb}^{3+} / \mathrm{PSA}$ gel composites reveal a homogeneous distribution of lanthanoides through the polymer covered by a shell of $\mathrm{NaCl}$.

\subsection{Effect of Cations on the Luminescence Properties Lanthanoid/PSA Complexes}

As it was discussed in the previous section, $\mathrm{Eu}^{3+} / \mathrm{PSA}$ and $\mathrm{Tb}^{3+} / \mathrm{PSA}$ complexes have carboxyl groups available to coordinate metal ions, affecting their spectroscopic properties and making these composites potentially useful as luminescent probes for different ions. In consequence, the ability of these composites to detect different cations, in aqueous solution, has been tested by recording the luminescence emission spectra of $\mathrm{Eu}^{3+} / \mathrm{PSA}$ and $\mathrm{Tb}^{3+} / \mathrm{PSA}$ in the presence of different cations: $\mathrm{Al}^{3+}$, $\mathrm{Ca}^{2+}, \mathrm{Ce}^{3+}, \mathrm{Cr}^{3+}, \mathrm{Cu}^{2+}, \mathrm{Hg}^{2+}, \mathrm{K}^{+}, \mathrm{Mg}^{2+}, \mathrm{Na}^{2+}, \mathrm{Ni}^{2+}, \mathrm{Pb}^{2+}$ and $\mathrm{Zn}^{2+}$, as aqueous solutions of $\mathrm{NO}_{3}{ }^{-}$, $\mathrm{Cl}^{-}$and $\mathrm{SCN}^{-}$(Section 2.1). The results indicate that the luminescence intensity of the composites is strongly dependent on the metal ion species. Figure 3 shows the quenching efficiency of metal ions on the luminescence intensity of composite, defined as $\left(I_{0}-I\right) / I_{0} \times 100 \%$, where $I_{0}$ and $I$ are the luminescence intensity without and with the addition of metal ions, respectively.
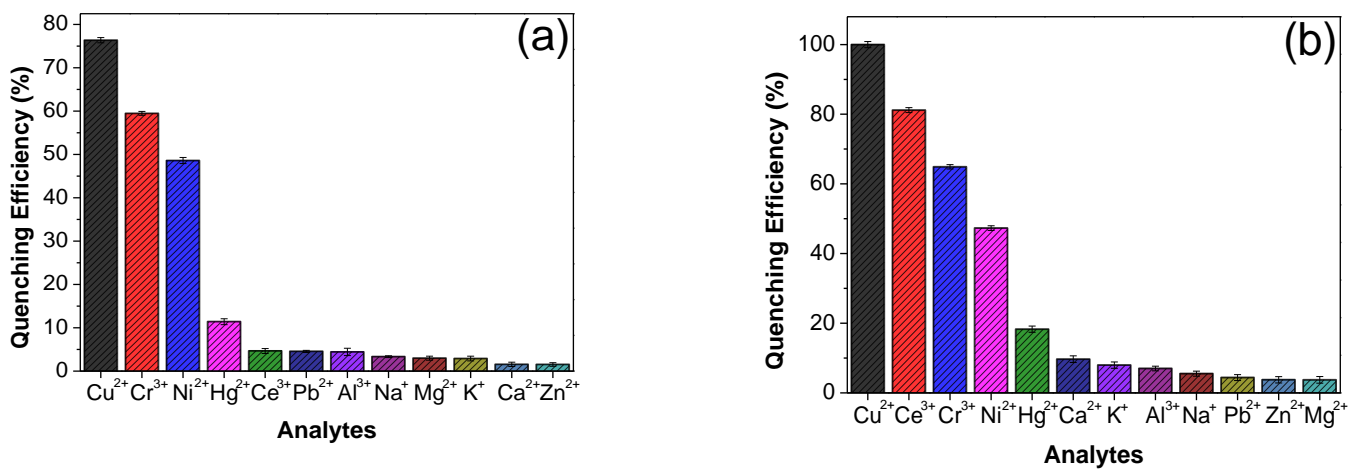

Figure 3. Quenching efficiency of $(\mathbf{a}) \mathrm{Eu}^{3+} / \mathrm{PSA}\left(\lambda_{\mathrm{em}}=616 \mathrm{~nm}\right)$ and $(\mathbf{b}) \mathrm{Tb}^{3+} / \mathrm{PSA}\left(\lambda_{\mathrm{em}}=545 \mathrm{~nm}\right)$ with different metal ions in aqueous solution.

Remarkably, $\mathrm{Cu}^{2+}$ is the most effective quencher for both composites. It completely quenches the emission of $\mathrm{Tb}^{3+} / \mathrm{PSA}$ at $545 \mathrm{~nm}$ (changing $\mathrm{Tb}^{3+} / \mathrm{PSA}$ emission from green to almost colorless in the presence of $\mathrm{Cu}^{2+}$ (Figure 4 ) and more than $70 \%$ of $\mathrm{Eu}^{3+} / \mathrm{PSA}$ emission at $616 \mathrm{~nm}$. The emission of the latter one changed from red to light red, while the other metals did not have such a pronounced effect on luminescence intensity for $\mathrm{Eu}^{3+} / \mathrm{PSA}$ (Figure 4). This indicates that $\mathrm{Tb}^{3+} / \mathrm{PSA}$ possesses a 
higher sensitivity to $\mathrm{Cu}^{2+}$, being a promising sensor for the detection of $\mathrm{Cu}^{2+}$ ions. This behavior will be discussed in terms of the suppression mechanism. In general, the transitional metal ions display a stronger effect in luminescence compared to alkaline metal ions and alkaline earth metals. The effect arises from unpaired d-electrons found in transition metal ions contrasting to the closed shell electron configuration of group I and II metal cations [28,38].
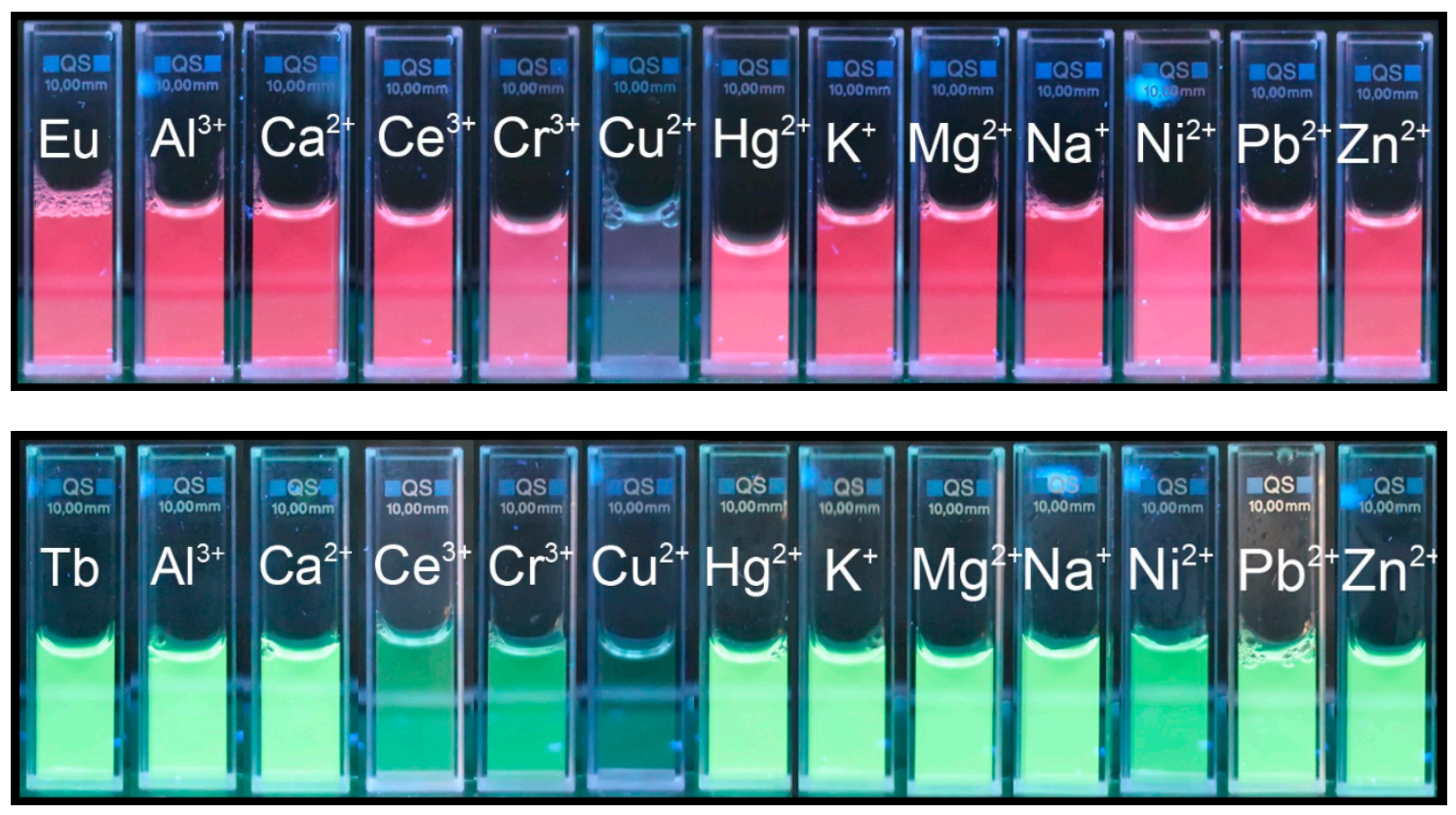

Figure 4. Fluorescence photographs of $\mathrm{Eu}^{3+} / \mathrm{PSA}$ (red) and $\mathrm{Tb}^{3+} / \mathrm{PSA}$ (green) alone (first to the left in each row), and in the presence of $3.33 \mathrm{mM}$ of metal ions under UV light (365 nm) in aqueous solution.

\subsection{Effect of Anions on Lanthanoid/PSA-Based Complex Properties}

In order to assess whether $\mathrm{Eu}^{3+} / \mathrm{PSA}$ and $\mathrm{Tb}^{3+} / \mathrm{PSA}$ composites can detect $\mathrm{Cu}^{2+}$ in the presence of other ions, the effects of several metal ions on the composite emission intensity were examined under the same experimental conditions. Firstly, the counter ion effect on the composite luminescence quenching was checked. For that, different sodium salts have been checked: $\mathrm{Br}^{-}, \mathrm{Cl}^{-}, \mathrm{CN}^{-}, \mathrm{F}^{-}, \mathrm{NO}_{2}^{-}$, $\mathrm{NO}_{3}{ }^{-}, \mathrm{OAc}^{-}, \mathrm{OH}^{-}$and $\mathrm{SCN}^{-}$. The results depicted in Figure 5 show no significant change in the luminescence emission intensity of $\mathrm{Eu}^{3+} / \mathrm{PSA}$ as the anion is varied (with variations around $5 \%$ at maximum, Figure 5 left) and, in consequence, it can be concluded that anions have no significant effect upon the detection of $\mathrm{Cu}^{2+}$ ions with $\mathrm{Eu}^{3+} / \mathrm{PSA}$.
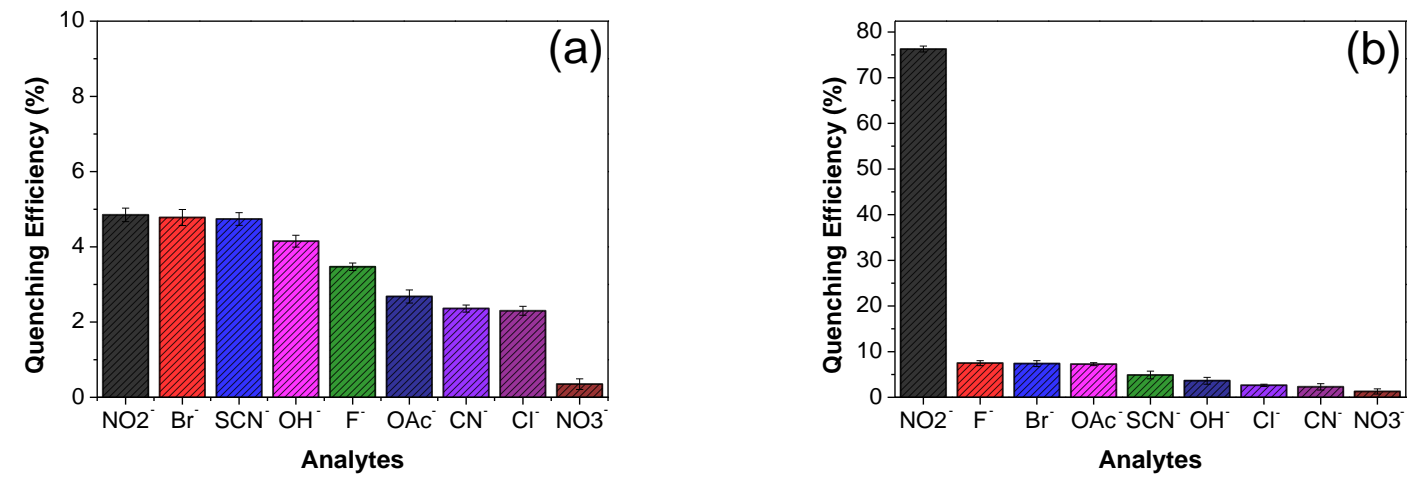

Figure 5. Quenching efficiency of $(\mathbf{a}) \mathrm{Eu}^{3+} / \mathrm{PSA}\left(\lambda_{\mathrm{em}}=616 \mathrm{~nm}\right)$ and $(\mathbf{b}) \mathrm{Tb}^{3+} / \mathrm{PSA}\left(\lambda_{\mathrm{em}}=545 \mathrm{~nm}\right)$ with different $\mathrm{Na}^{+}$salts in aqueous solution. 
In contrast, the luminescence emission of $\mathrm{Tb}^{3+} / \mathrm{PSA}$ composite is effectively quenched (75\%) by nitrite ion. This can be attributed to energy transfer from $\mathrm{Tb}^{3+}$ to $\mathrm{NO}_{2}{ }^{-}$[6] and, consequently $\mathrm{NO}_{2}{ }^{-}$ might be considered as an interferent for the $\mathrm{Cu}^{2+}$ detection for the $\mathrm{Tb}^{3+} / \mathrm{PSA}$ composite. The energy transfer may occur from $\mathrm{Tb}^{3+}$ to $\mathrm{NO}_{2}{ }^{-}$, due the ${ }^{5} D_{4}$ energy level of $\mathrm{Tb}^{3+}$ that matches with $T_{1}$ energy level of $\mathrm{NO}_{2}{ }^{-}$; the same does not happen with $\mathrm{Eu}^{3+}$ [6].

In order to gain an insight into the potential selective detection of $\mathrm{Eu}^{3+} / \mathrm{PSA}$ and $\mathrm{Tb}^{3+} / \mathrm{PSA}$ composite toward $\mathrm{Cu}^{2+}$ in aqueous solution, the selectivity detection and the potential interference with other metal ions was studied by using $\mathrm{Eu}^{3+} / \mathrm{PSA}$ and $\mathrm{Tb}^{3+} / \mathrm{PSA}$, and $\mathrm{Cu}^{2+}(3.33 \mathrm{M})$ in the presence of other metal ions (at equimolar concentrations). In both cases, the composite emission quenching by $\mathrm{Cu}^{2+}$ was hardly affected, as shown in Figure S2. The results indicate that $\mathrm{Cu}^{2+}$ detection is weakly perturbed by coexisting cations in solutions, confirming that the composites could selectively detect $\mathrm{Cu}^{2+}$, even in the presence of the other competing metal ions, clearly suggesting the potential of these composites as $\mathrm{Cu}^{2+}$ probes. The high selectivity of these composites towards $\mathrm{Cu}^{2+}$ could take place via interactions between functional sites, such as the uncoordinated carboxylic oxygen atom of PSA with $\mathrm{Cu}^{2+}$ ions, which will be discussed as follows.

\subsection{On the Interaction Mechanism Between $\mathrm{Cu}(\mathrm{II})$ and Lanthanoid/PSA-Based Complexes}

Having $\mathrm{Cu}^{2+}$ ions showed high interaction with composites, the nature of the quenching process should be unveiled. For that, the lifetimes of $\mathrm{Eu}^{3+} / \mathrm{PSA}$ and $\mathrm{Tb}^{3+} / \mathrm{PSA}$ composites were measured in absence, and in the presence of different concentrations of $\mathrm{Cu}^{2+}$. The decay curves for $\mathrm{Eu}^{3+} / \mathrm{PSA}$ and $\mathrm{Tb}^{3+} / \mathrm{PSA}$ in the presence of variable concentrations of $\mathrm{Cu}^{2+}$ were also monoexponencial, which indicates that $\mathrm{Cu}^{2+}$ does not replace the lanthanoids in the PSA chain, which would give rise to biexponential decays, due to the simultaneous emission of the composite and the free lanthanoids.

The lifetimes fit properly the Stern-Volmer equation.

$$
\tau_{0} / \tau=1+K_{\mathrm{SV}, \mathrm{D}}[\mathrm{Q}]
$$

where $\tau_{0}$ and $\tau$ are the composite lifetime before and after the incorporation of the metal cation respectively, $K_{\mathrm{SV}, \mathrm{D}}$ is the dynamic Stern-Volmer constant and $[\mathrm{Q}]=\left[\mathrm{Cu}^{2+}\right]$, as shown in Figure 6. The computed dynamic Stern-Volmer constants are equal to $44.0( \pm 0.5)$ and $583( \pm 7) \mathrm{M}^{-1}$ for $\mathrm{Eu}^{3+} / \mathrm{PSA}$ and $\mathrm{Tb}^{3+} / \mathrm{PSA}$, respectively, which are an order of magnitude lower than the ones obtained with the emission intensities Stern-Volmer plot (580 and $5655 \mathrm{M}^{-1}$, for the same composites, respectively). These results confirm that both static and dynamic quenching are simultaneously taking place $[11,26,39,40]$.
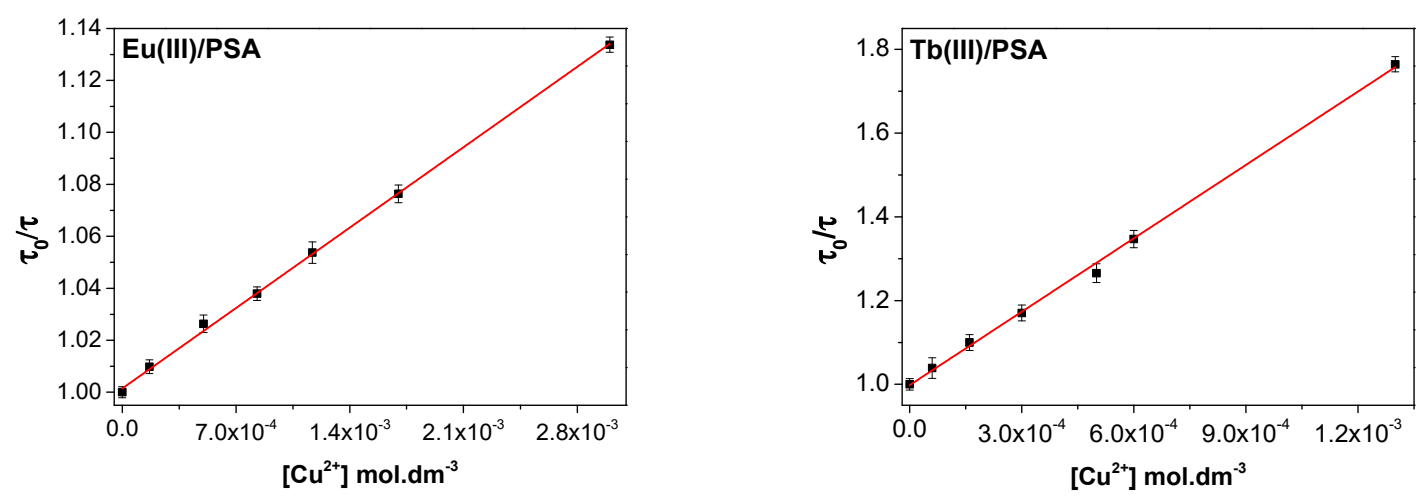

Figure 6. Stern-Volmer plot of $\mathrm{Eu}^{3+} / \mathrm{PSA}$ and $\mathrm{Tb}^{3+} / \mathrm{PSA}$ lifetimes with different $\mathrm{Cu}^{2+}$ concentrations.

The $\mathrm{Cu}^{2+}$ paramagnetism contributes to the quenching of the fluorescence emission by increasing the intersystem crossing process $[29,41-44]$. The higher $\mathrm{Tb}^{3+} / \mathrm{PSA}$ sensitivity to $\mathrm{Cu}^{2+}$ with respect to that of $\mathrm{Eu}^{3+} / \mathrm{PSA}$ could be partially due to the overlap between the absorption spectra of both $\mathrm{Tb}^{3+} / \mathrm{PSA}$ and $\mathrm{Cu}^{2+}$ (spectra not shown), which is likely to significantly diminish $\mathrm{Tb}^{3+} / \mathrm{PSA}^{2}$ emission 
intensity $[28,45,46]$. In general, PSA plays an important role in the quenching process, due to its ability to coordinate $\mathrm{Cu}^{2+}$ ions. This interaction can enhance the proximity between the composites and $\mathrm{Cu}^{2+}$ promoting a dynamic quenching and, simultaneously, form a new non-luminescent composite. We hypothesize that the polymer may act as a surface, which promotes sensor luminescence quenching by adsorbing $\mathrm{Cu}^{2+}$ ions through the complexation with the polymer carboxylic groups, as will be confirmed by EDX mapping [47]. As stated before, such an interaction can also be used for the application of these composites on the selective removal of $\mathrm{Cu}^{2+}$ as an added value metal.

\subsection{Effect of $p H$ and Quenching Rate}

The emission intensity of $\mathrm{Eu}^{3+} / \mathrm{PSA} / \mathrm{Cu}^{2+}$ and $\mathrm{Tb}^{3+} / \mathrm{PSA} / \mathrm{Cu}^{2+}$ composites, with three different $\mathrm{Cu}^{2+}$ concentrations for each system, were recorded at 616 and $545 \mathrm{~nm}$ at several delays after sample preparations (Figure S3), showing that, independently of $\mathrm{Cu}^{2+}$ concentrations, the emission intensity reaches an equilibrium almost instantaneously (around a minute), remaining constant for almost a week [48], showing the great stability of the composites. Additionally, the emission intensities of $\mathrm{Eu}^{3+} / \mathrm{PSA} / \mathrm{Cu}^{2+}$ and $\mathrm{Tb}^{3+} / \mathrm{PSA} / \mathrm{Cu}^{2+}$ composites, at 616 and $545 \mathrm{~nm}$, respectively, recorded for solutions with different $\mathrm{pH}$ values (Figure S4) were approximately the same, proving that composites were stable over a wide $\mathrm{pH}$ range (6-11), and indicating their potential applications on a large $\mathrm{pH}$ range, including environmental and physiological conditions.

\subsection{Sensitivity of $\mathrm{Eu}^{3+} / \mathrm{PSA}$ and $\mathrm{Tb}^{3+} / \mathrm{PSA}$ to $\mathrm{Cu}^{2+}$}

Sensitivity is a key factor to evaluate the performance of a probe to determine traces of an analyte and also for remediation purposes. To further examine the $\mathrm{Eu}^{3+} / \mathrm{PSA}$ and $\mathrm{Tb}^{3+} / \mathrm{PSA}$ composite sensing sensitivity towards $\mathrm{Cu}^{2+}$, their luminescence emission quenching by $\mathrm{CuCl}_{2}$ (at concentrations ranging from $0.33 \mathrm{mM}$ to $3.33 \mathrm{mM}$ ) were studied. The emission luminescence spectra of composites are shown in Supplementary Information (Figures S5-S8). Moreover, Figure 7a shows the emission luminescence intensity of $\mathrm{Eu}^{3+} / \mathrm{PSA}$, at $616 \mathrm{~nm}$ which gradually decreases with $\mathrm{Cu}^{2+}$ concentration. When the concentration $3.33 \mathrm{mM} \mathrm{Cu}^{2+}$ is reached, the quenching efficiency is above $75 \%$.
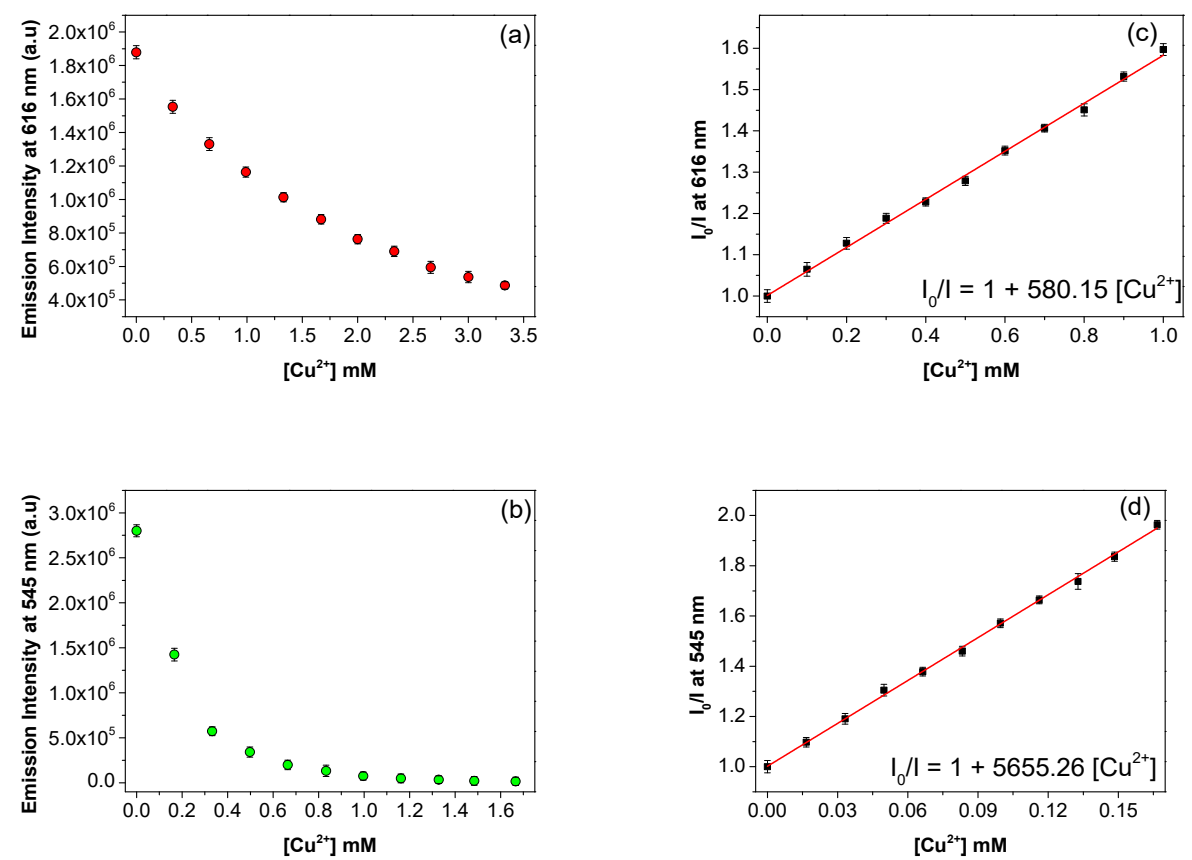

Figure 7. Emission intensities of (a) Eu ${ }^{3+} / \mathrm{PSA}\left({ }^{5} D_{0} \rightarrow{ }^{7} F_{2}\right)$ transition, (b) $\mathrm{Tb}^{3+} / \mathrm{PSA}\left({ }^{5} D_{4} \rightarrow{ }^{7} F_{5}\right)$ transition and Stern-Volmer plots of (c) $\mathrm{Eu}^{3+} / \mathrm{PSA}$ and (d) $\mathrm{Tb}^{3+} / \mathrm{PSA}$ with lower concentrations of $\mathrm{Cu}^{2+}$. 
Figure 7c shows the ratio of emission intensities in absence $\left(I_{0}\right)$ and presence of $\mathrm{Cu}^{2+}(I)$ of ${ }^{5} D_{0}-{ }^{7} F_{2}$ emission at $616 \mathrm{~nm}$ versus the concentration of $\mathrm{Cu}^{2+}$ for metal ion concentrations lower than $10^{-3} \mathrm{M}$. In this concentration range, $\mathrm{Eu}^{3+} / \mathrm{PSA}$ emission quenching follows the Stern-Volmer equation (Equation (1)). A good determination coefficient $\left(R^{2}=0.997\right)$ was obtained for the fitting of Equation (1) to experimental data, leading to a Stern-Volmer constant, $K_{\mathrm{SV}}$, equal to $580( \pm 1) \mathrm{M}^{-1}$. The limit of detection (LOD) for ions $\mathrm{Cu}^{2+}$ has been calculated by using the equation: $3 \sigma / k$, where $\sigma$ is the standard error and $k$ the slope. The LOD has been calculated as $3.06 \times 10^{-5} \mathrm{M}$ (corresponding to $1.94 \mathrm{ppm}$ ). Therefore, $\mathrm{Eu}^{3+} / \mathrm{PSA}$ presents an excellent sensitivity towards $\mathrm{Cu}^{2+}$. Similar sensitivity tests were carried out with $\mathrm{Tb}^{3+} / \mathrm{PSA}$ composites, and results are shown in Figure $7 \mathrm{~b}$, d. The fluorescence intensity at $545 \mathrm{~nm}$ is drastically quenched by the gradual increase of the concentration of $\mathrm{Cu}^{2+}$ and for $\mathrm{Cu}^{2+}$ concentrations below $1.8 \times 10^{-3} \mathrm{M}$, the Stern-Volmer equation is followed (Figure $7 \mathrm{~d}$ ). The calculated $K_{\mathrm{SV}}$ value is $5655( \pm 68) \mathrm{M}^{-1}$ and the limit of detection for $\mathrm{Cu}^{2+}$ is $3.56 \times 10^{-6} \mathrm{M}(0.226 \mathrm{ppm})$, indicating a higher sensitivity to $\mathrm{Cu}^{2+}$ when compared to $\mathrm{Eu}^{3+} / \mathrm{PSA}$. $\mathrm{K}_{\mathrm{SV}}$ values obtained for $\mathrm{Cu}^{2+}$ in both composites are relatively high, and can be compared with the values obtained for other compounds previously used for $\mathrm{Cu}^{2+}$ detection (Table 2). This indicates that both composites have great potential for application in $\mathrm{Cu}^{2+}$ ion sensing, especially $\mathrm{Tb}^{3+} / \mathrm{PSA}$, which shows greater sensitivity.

Table 2. Stern-Volmer constant for the quenching of the emission of several lanthanoid-based sensors by $\mathrm{Cu}^{2+}$.

\begin{tabular}{lcc}
\hline \multicolumn{1}{c}{ Luminescent Material } & $\boldsymbol{K}_{\mathbf{s v}}\left(\mathbf{M}^{\mathbf{- 1}} \mathbf{)}\right.$ & Reference \\
\hline$\left[\mathrm{Eu}(\mathrm{pdc})_{1.5}(\mathrm{dmf})\right] \cdot(\mathrm{DMF})_{0.5}\left(\mathrm{H}_{2} \mathrm{O}\right)_{0.5}$ & 89 & {$[49]$} \\
$\mathrm{Eu}^{3+} / \mathrm{PSA}$ & 580 & This Work \\
$\left\{\left[\mathrm{Eu}_{2}(\mathrm{abtc})_{1.5}\left(\mathrm{H}_{2} \mathrm{O}\right)_{3}(\mathrm{DMA})\right] \cdot \mathrm{H}_{2} \mathrm{O} \cdot \mathrm{DMA}\right\}_{\mathrm{n}}$ & 529 & {$[50]$} \\
$\left\{\left[\mathrm{Eu}(\mathrm{HL})(\mathrm{L})\left(\mathrm{H}_{2} \mathrm{O}\right)_{2}\right]_{2} \mathrm{H}_{2} \mathrm{O}\right\} \mathrm{n}$ & 116 & {$[43]$} \\
$\left\{\left[\mathrm{Eu}(\mathrm{L})(\mathrm{ox})_{0.5}\left(\mathrm{H}_{2} \mathrm{O}\right)_{2}\right]_{-} \mathrm{H}_{2} \mathrm{O}\right\} \mathrm{n}$ & 2074 & {$[51]$} \\
$\mathrm{Tb}{ }^{3+} / \mathrm{PSA}$ & 5655 & This work \\
$\mathrm{Tb}-\mathrm{SA}$ & 6298 & {$[52]$} \\
\hline
\end{tabular}

\subsection{Characterization of Solid Lanthanoid/PSA Composites Containing $\mathrm{Cu}^{2+}$}

SEM micrographs of the composites obtained with the objective of investigating the morphology and structure of the composites after contact with $\mathrm{Cu}^{2+}$ (Figure S9), indicate that the structure maintains its integrity and, therefore, the quenching effect is not a consequence of structure collapse. The EDX spectra of composite, obtained after immersion in a $\mathrm{Cu}^{2+}$ solution, show the presence of these ions, suggesting a strong interaction between $\mathrm{Cu}^{2+}$ and the composites. To support this hypotheses, elemental EDX maps have been made, and confirm the interaction of $\mathrm{Cu}^{2+}$ with the composites in the region where the composites are not coated with $\mathrm{NaCl}$ crystals. This also shows that most of the $\mathrm{Cu}^{2+}$ added is bound to the composites having a uniform distribution in the same region that $\mathrm{Eu}$ and $\mathrm{Tb}$ (Figure 8 and Figure S10, respectively). From the elemental maps, we can also conclude that in the $\mathrm{Eu}^{3+} / \mathrm{PSA}$ and $\mathrm{Tb}^{3+} / \mathrm{PSA}$ composites a simultaneous interaction of the polymer with both the lanthanoid and $\mathrm{Cu}^{2+}$ ions is produced; i.e., $\mathrm{Cu}^{2+}$ ions do not replace the lanthanoides in the PSA chain, in good agreement with the previously discussed lanthanoids lifetime results. The surface of the composites is characterized by a high content of oxygen, making available sites of interaction with $\mathrm{Cu}^{2+}$ and other metallic ions. We can therefore suggest that the main mechanism of the composite luminescent quenching induced by metal ions is the $\mathrm{Cu}^{2+}$ complexation, with the composite through the carboxylate groups of $\mathrm{Ln}^{3+} / \mathrm{PSA}$. 

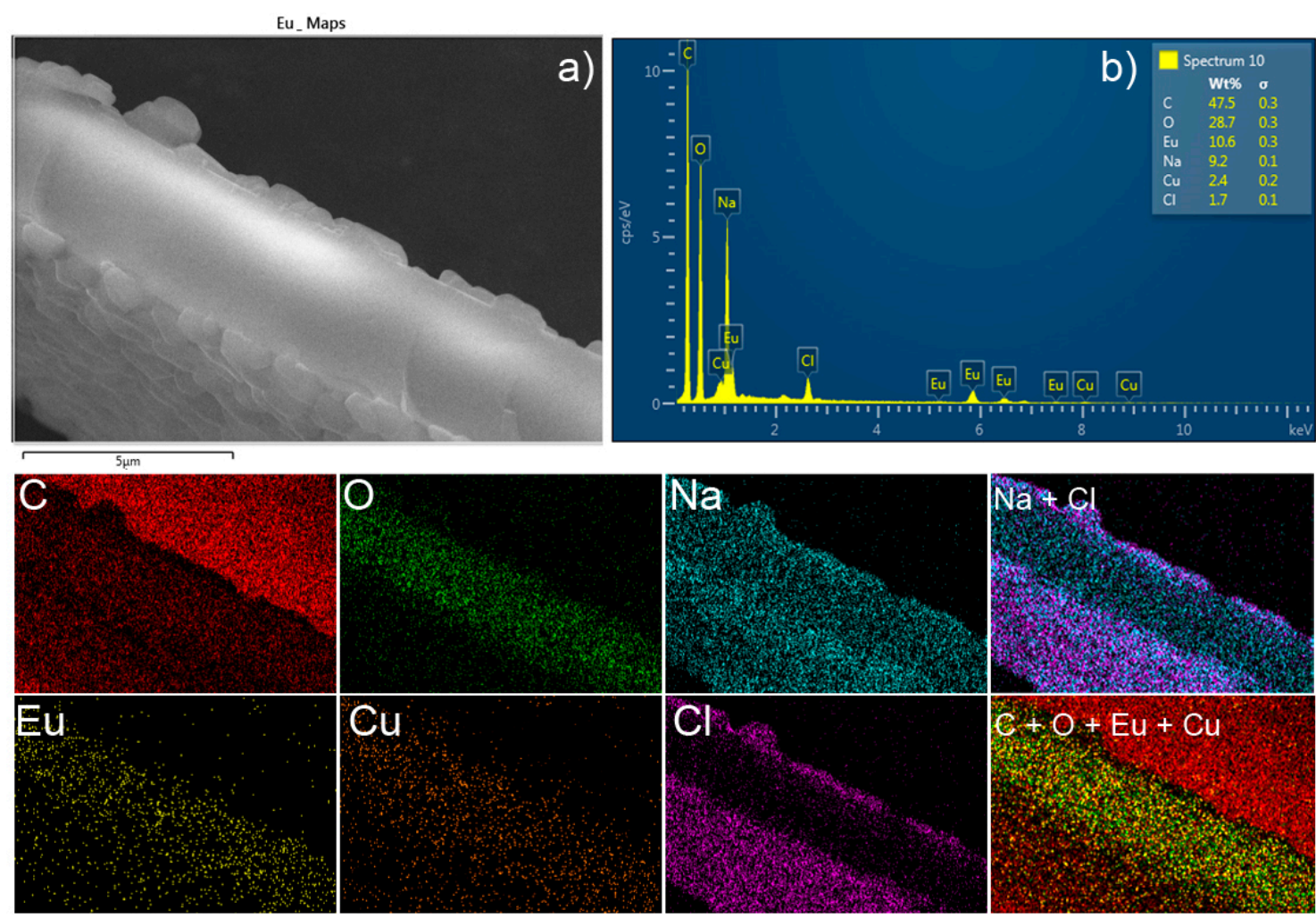

Figure 8. (a) SEM micrography, (b) EDX spectra and elemental maps of $\mathrm{Eu}^{3+} / \mathrm{PSA}$ after contact with $\mathrm{Cu}^{2+}$. The right-hand figures represent the combined elemental maps; for the sake of clarity, the elemental maps of counterions $(\mathrm{Na}$ and $\mathrm{Cl})$ are represented in a separated figure.

\section{Conclusions}

Two highly luminescent water soluble stable metal-organic composites $\left(\mathrm{Eu}^{3+} / \mathrm{PSA}\right.$ and $\left.\mathrm{Tb}^{3+} / \mathrm{PSA}\right)$ were prepared, showing a significant emission quenching in the presence of $\mathrm{Cu}^{2+}$, when compared with a set of other metal ions: $\mathrm{Al}^{3+}, \mathrm{Ca}^{2+}, \mathrm{Ce}^{3+}, \mathrm{Cr}^{3+}, \mathrm{Hg}^{2+}, \mathrm{K}^{+}, \mathrm{Mg}^{2+}, \mathrm{Na}^{+}, \mathrm{Ni}^{2+}, \mathrm{Pb}^{2+}$ and $\mathrm{Zn}^{2+}$ that, in general, do not compete with copper ions for the composite. Polymer composite emission intensities and lifetimes in the presence of $\mathrm{Cu}^{2+}$ follow Stern-Volmer kinetics, indicating that both static and dynamic quenching processes take place simultaneously, with the former being one order of magnitude higher for both composites. This probes that complex formation is the main interaction mechanism between the lanthanoid/PSA composites and $\mathrm{Cu}^{2+}$, likely through the polymer carboxylate groups. The composite shows a fast response to the presence of $\mathrm{Cu}^{2+}$ (less than one minute) and linear for $\mathrm{Cu}^{2+}$ concentration below $1 \mathrm{mM}\left(\mathrm{Eu}^{3+} / \mathrm{PSA}\right)$ and $1.8 \times 10^{-3} \mathrm{M}\left(\mathrm{Tb}^{3+} / \mathrm{PSA}\right)$, within an extended $\mathrm{pH}$ range (6 to 11), and with detection limits of 1.94 and $0.22 \mathrm{ppm}$, in the case of $\mathrm{Eu}^{3+} / \mathrm{PSA}$ and $\mathrm{Tb}^{3+} / \mathrm{PSA}$, respectively. In our experimental conditions, no competition has been detected between the lanthanides and copper ions, indicating that the PSA has carboxylate groups available for coordination after the interaction with lanthanoid ions. Additionally, nitrite ions also promote high quenching efficiency for $\mathrm{Tb}^{3+} / \mathrm{PSA}$ composite through an energy transfer process. The experimental results reported have unraveled a new promising method for a simple and reliable monitoring or removal of $\mathrm{Cu}^{2+}$ from different media. Moreover, these composites can be used both as aqueous solution and in a gel state, enlarging the potential range of their practical applications.

Supplementary Materials: The following are available online at http://www.mdpi.com/2073-4360/12/6/1314/s1, Figure S1: EDX spectra and elemental maps of freeze-dried $\mathrm{Eu}^{3+} / \mathrm{PSA}$ (left) and $\mathrm{Tb}^{3+} / \mathrm{PSA}$ (right), Figure S2: Comparison of emission intensity of $\mathrm{Eu}^{3+} / \mathrm{PSA}$ at $616 \mathrm{~nm}$ (left) and $\mathrm{Tb}^{3+} / \mathrm{PSA}$ at $545 \mathrm{~nm}$ (right) of composites alone $\left(I_{0}\right)$ and interacting with different metal ions in aqueous solution under the same conditions $(I)$, Figure S3: Emission intensities of (A) $\mathrm{Eu}^{3+} / \mathrm{PSA}$ at $616 \mathrm{~nm}$ (left) and (B) $\mathrm{Tb}^{3+} / \mathrm{PSA}$ at $545 \mathrm{~nm}$ (right) with different concentration of $\mathrm{Cu}^{2+}$ ions in aqueous solution at several delays after sample preparation, Figure S4: Effects of $\mathrm{pH}$ on the 
emission intensities of (A) $\mathrm{Eu}^{3+} / \mathrm{PSA}$ at $616 \mathrm{~nm}$ and (left) (B) $\mathrm{Tb}^{3+} / \mathrm{PSA}$ at $545 \mathrm{~nm}$ (right), without $\mathrm{Cu}^{2+}$ (black) and with $3.33 \mathrm{mM}$ of $\mathrm{Cu}^{2+}$ (red), Figure S5: Emission spectra of $\mathrm{Eu}^{3+} / \mathrm{PSA},{ }^{5} \mathrm{D}_{0} \rightarrow{ }^{7} \mathrm{~F}_{2}$ transition emission intensity at $616 \mathrm{~nm}$ (inset) of $\mathrm{Eu}^{3+} / \mathrm{PSA}$ with different concentrations of $\mathrm{Cu}^{2+}$, T S6: Emission spectra of $\mathrm{Eu}^{3+} / \mathrm{PSA}^{2}$ and Stern-Volmer plot of ${ }^{5} D_{0} \rightarrow{ }^{7} F_{2}$ transition at $616 \mathrm{~nm}$ (inset) for $\mathrm{Eu}^{3+} / \mathrm{PSA}$ with lower concentrations of $\mathrm{Cu}^{2+}$, Figure S7: Emission spectra of $\mathrm{Tb}^{3+} / \mathrm{PSA}$ and ${ }^{5} \mathrm{D}_{4} \rightarrow{ }^{7} F_{5}$ transition intensities at $545 \mathrm{~nm}$ (inset) for Tb ${ }^{3+} / \mathrm{PSA}$ with different concentrations of $\mathrm{Cu}^{2+}$, Figure S8: Emission spectra of $\mathrm{Tb}^{3+} / \mathrm{PSA}$ and Stern-Volmer plot of ${ }^{5} \mathrm{D}_{4} \rightarrow{ }^{7} F_{5}$ transition at $545 \mathrm{~nm}$ (inset) for $\mathrm{Tb}^{3+} / \mathrm{PSA}$ with lower concentrations of $\mathrm{Cu}^{2+}$, SEM micrographs of (a) $\mathrm{Eu}^{3+} / \mathrm{PSA}$, (b) $\mathrm{Tb}^{3+} / \mathrm{PSA}$ before contact with $\mathrm{Cu}^{2+}$ and (c) $\mathrm{Eu}^{3+} / \mathrm{PSA}$, (d) $\mathrm{Tb}^{3+} / \mathrm{PSA}$ after contact with $\mathrm{Cu}^{2+}$. Magnification $\times 500$, Figure S10: (a) SEM micrography, (b) EDX spectra and elemental maps of $\mathrm{Tb}^{3+} / \mathrm{PSA}$ after contact with $\mathrm{Cu}^{2+}$.

Author Contributions: Conceptualization, A.F.Y.M., A.A.C.C.P. and A.J.M.V.; Data curation, A.F.Y.M., M.J.T. and A.J.M.V.; Formal analysis, A.F.Y.M., A.A.C.C.P., M.J.T. and A.J.M.V.; Investigation, A.F.Y.M.; Methodology, A.F.Y.M., M.J.T. and A.J.M.V.; Project administration, A.J.M.V., A.A.C.C.P.; Resources, A.A.C.C.P., M.J.T. and A.J.M.V.; Supervision, A.A.C.C.P., M.J.T. and A.J.M.V.; Writing-original draft, A.F.Y.M., M.J.T. and A.J.M.V.; Writing-review and editing, A.F.Y.M., A.A.C.C.P., M.J.T. and A.J.M.V. All the authors participated in the analysis of the results. All authors have read and agreed to the published version of the manuscript.

Funding: This work was funded by the Coimbra Chemistry Centre which is supported by the Fundação para a Ciência e a Tecnologia (FCT) through the programmes UID/QUI/UI0313/2020 and COMPETE.

Acknowledgments: A.F.Y.M. acknowledges financial support from the Conselho Nacional de Desenvolvimento Científico e Tecnológico (CNPq-Brazil)—Science without borders, through the PhD grants (Grant number 249241/2013-7).

Conflicts of Interest: The authors declare no conflict of interest.

\section{References}

1. Xu, G.; Nie, P.; Dou, H.; Ding, B.; Li, L.; Zhang, X. Exploring metal organic frameworks for energy storage in batteries and supercapacitors. Mater. Today 2017, 20, 191-209. [CrossRef]

2. Yao, C.-X.; Zhao, N.; Liu, J.-C.; Chen, L.-J.; Liu, J.-M.; Fang, G.; Wang, S. Recent Progress on Luminescent Metal-Organic Framework-Involved Hybrid Materials for Rapid Determination of Contaminants in Environment and Food. Polymers 2020, 12, 691. [CrossRef]

3. Zhu, L.; Liu, X.-Q.; Jiang, H.-L.; Sun, L.-B. Metal-Organic Frameworks for Heterogeneous Basic Catalysis. Chem. Rev. 2017, 117, 8129-8176. [CrossRef] [PubMed]

4. He, L.; Peng, Z.W.; Jiang, Z.W.; Tang, X.Q.; Huang, C.; Li, Y.F. Novel Iron(III)-Based Metal-Organic Gels with Superior Catalytic Performance toward Luminol Chemiluminescence. ACS Appl. Mater. Interfaces 2017, 9, 31834-31840. [CrossRef] [PubMed]

5. Khajavi, H.; Gascon, J.; Schins, J.M.; Siebbeles, L.D.A.; Kapteijn, F.; Kapteijn, F. Unraveling the Optoelectronic and Photochemical Behavior of $\mathrm{Zn}_{4} \mathrm{O}$-Based Metal Organic Frameworks. J. Phys. Chem. C 2011, 115, 12487-12493. [CrossRef]

6. Yuan, D.; Zhang, Y.D.; Jiang, Z.W.; Peng, Z.W.; Huang, C.; Li, Y.F. Tb-containing metal-organic gel with high stability for visual sensing of nitrite. Mater. Lett. 2018, 211, 157-160. [CrossRef]

7. Lloyd, G.O.; Steed, J.W. Anion-tuning of supramolecular gel properties. Nat. Chem. 2009, 1, 437-442. [CrossRef]

8. Sutar, P.; Maji, T.K. Coordination polymer gels: Soft metal-organic supramolecular materials and versatile applications. Chem. Commun. 2016, 52, 8055-8074. [CrossRef]

9. Zhang, J.; Su, C.-Y. Metal-organic gels: From discrete metallogelators to coordination polymers. Coord. Chem. Rev. 2013, 257, 1373-1408. [CrossRef]

10. Tian, D.; Li, Y.; Chen, R.-Y.; Chang, Z.; Wang, G.; Bu, X.-H. A luminescent metal-organic framework demonstrating ideal detection ability for nitroaromatic explosives. J. Mater. Chem. A 2014, 2, 1465-1470. [CrossRef]

11. Lakowicz, J.R. (Ed.) Principles of Fluorescence Spectroscopy; Springer US: Boston, MA, USA, 2006; ISBN 978-0-387-31278-1.

12. Liu, J.; Zuo, W.; Zhang, W.; Liu, J.; Wang, Z.; Yang, Z.; Wang, B. Europium(III) complex-functionalized magnetic nanoparticle as a chemosensor for ultrasensitive detection and removal of copper(II) from aqueous solution. Nanoscale 2014, 6, 11473-11478. [CrossRef] [PubMed] 
13. Aksuner, N.; Henden, E.; Yilmaz, I.; Çukurovalı, A.; Yılmaz, I. A highly sensitive and selective fluorescent sensor for the determination of copper(II) based on a schiff base. Dye. Pigment. 2009, 83, 211-217. [CrossRef]

14. Kluczka, J. Removal of Boron and Manganese Ions from Wet-Flue Gas Desulfurization Wastewater by Hybrid Chitosan-Zirconium Sorbent. Polymers 2020, 12, 635. [CrossRef]

15. Vareda, J.P.; Valente, A.J.; Durães, L. Assessment of heavy metal pollution from anthropogenic activities and remediation strategies: A review. J. Environ. Manag. 2019, 246, 101-118. [CrossRef] [PubMed]

16. Reddyprasad, P.; Imae, T. Selective detection of copper ion in water by tetradentate ligand sensor. J. Taiwan Inst. Chem. Eng. 2017, 72, 194-199. [CrossRef]

17. Ghaedi, M.; Shokrollahi, A.; Kianfar, A.; Mirsadeghi, A.; Pourfarokhi, A.; Soylak, M. The determination of some heavy metals in food samples by flame atomic absorption spectrometry after their separation-preconcentration on bis salicyl aldehyde, 1,3 propan diimine (BSPDI) loaded on activated carbon. J. Hazard. Mater. 2008, 154, 128-134. [CrossRef] [PubMed]

18. Ghaedi, M.; Tashkhourian, J.; Montazerozohori, M.; Biyareh, M.N.; Sadeghian, B. Highly selective and sensitive determination of copper ion by two novel optical sensors. Arab. J. Chem. 2017, 10, S2319-S2326. [CrossRef]

19. Gómez, M.R.; Cerutti, S.; Sombra, L.L.; Silva, M.F.; Martínez, L.D. Determination of heavy metals for the quality control in argentinian herbal medicines by ETAAS and ICP-OES. Food Chem. Toxicol. 2007, 45, 1060-1064. [CrossRef]

20. Wang, Q.; Chen, K.; Qu, Y.; Li, K.; Zhang, Y.; Fu, E. Hairy Fluorescent Nanospheres Based on Polyelectrolyte Brush for Highly Sensitive Determination of $\mathrm{Cu}(\mathrm{II})$. Polymers 2020, 12, 577. [CrossRef]

21. Zeng, C.-H.; Meng, X.-T.; Xu, S.-S.; Han, L.-J.; Zhong, S.; Jia, M.-Y. A polymorphic lanthanide complex as selective $\mathrm{Co}^{2+}$ sensor and luminescent timer. Sens. Actuators B Chem. 2015, 221, 127-135. [CrossRef]

22. Du, J.-L.; Zhang, X.-Y.; Li, C.-P.; Gao, J.-P.; Hou, J.-X.; Jing, X.; Mu, Y.-J.; Li, L.-J. A bi-functional luminescent $\mathrm{Zn}(\mathrm{II})-\mathrm{MOF}$ for detection of nitroaromatic explosives and $\mathrm{Fe}^{3+}$ ions. Sens. Actuators B Chem. 2018, 257, $207-213$. [CrossRef]

23. Chaudhary, S.; Kumar, S.; Umar, A.; Singh, J.; Rawat, M.; Mehta, S. Europium-doped gadolinium oxide nanoparticles: A potential photoluminescencent probe for highly selective and sensitive detection of $\mathrm{Fe}^{3+}$ and $\mathrm{Cr}^{3+}$ ions. Sens. Actuators B Chem. 2017, 243, 579-588. [CrossRef]

24. Matsushita, A.F.; Filho, C.M.; Piñeiro, M.; Pais, A.A.C.C.; Valente, A.J.M. Effect of Eu(III) and Tb(III) chloride on the gelification behavior of poly(sodium acrylate). J. Mol. Liq. 2018, 264, 205-214. [CrossRef]

25. Qi, X.; Wang, Z.; Ma, S.; Wu, L.; Yang, S.; Xu, J. Complexation behavior of poly(acrylic acid) and lanthanide ions. Polymers 2014, 55, 1183-1189. [CrossRef]

26. Chen, C.; Zhang, X.; Gao, P.; Hu, M. A water stable europium coordination polymer as fluorescent sensor for detecting $\mathrm{Fe}^{3+}, \mathrm{CrO}_{4}{ }^{2-}$, and $\mathrm{Cr}_{2} \mathrm{O}_{7}{ }^{2-}$ ions. J. Solid State Chem. 2018, 258, 86-92. [CrossRef]

27. Tang, K.; Ma, Q.; Zhan, Q.; Wang, Q. An intelligent copper(II) luminescent sensor using europium narrow emissions based on titania hybrid material. Opt. Mater. 2014, 36, 1520-1524. [CrossRef]

28. Bogale, R.F.; Chen, Y.; Ye, J.; Yang, Y.; Rauf, A.; Duan, L.; Tian, P.; Ning, G. Highly selective and sensitive detection of 4-nitrophenol and $\mathrm{Fe}^{3+}$ ion based on a luminescent layered terbium (III) coordination polymer. Sens. Actuators B Chem. 2017, 245, 171-178. [CrossRef]

29. Yang, W.; Feng, J.; Zhang, H. Facile and rapid fabrication of nanostructured lanthanide coordination polymers as selective luminescent probes in aqueous solution. J. Mater. Chem. 2012, 22, 6819. [CrossRef]

30. Costa, D.; Burrows, H.D.; Miguel, M. Changes in Hydration of Lanthanide Ions on Binding to DNA in Aqueous Solution. Langmuir 2005, 21, 10492-10496. [CrossRef]

31. Horrocks, W.D.; Sudnick, D.R. Lanthanide ion probes of structure in biology. Laser-induced luminescence decay constants provide a direct measure of the number of metal-coordinated water molecules. J. Am. Chem. Soc. 1979, 101, 334-340. [CrossRef]

32. Horrocks, W.D.; Schmidt, G.F.; Sudnick, D.R.; Kittrell, C.; Bernheim, R.A. Laser-induced lanthanide ion luminescence lifetime measurements by direct excitation of metal ion levels. A new class of structural probe for calcium-binding proteins and nucleic acids. J. Am. Chem. Soc. 1977, 99, 2378-2380. [CrossRef] [PubMed]

33. Tapia, M.J.; Burrows, H.D. Cation Polyelectrolyte Interactions in Aqueous Sodium Poly(vinyl sulfonate) as Seen by $\mathrm{Ce}^{3+}$ to $\mathrm{Tb}^{3+}$ Energy Transfer. Langmuir 2002, 18, 1872-1876. [CrossRef] 
34. Tapia, M.J.; Burrows, H.D.; Azenha, M.; Miguel, M.; Pais, A.A.C.C.; Sarraguca, J. Cation Association with Sodium Dodecyl Sulfate Micelles As Seen by Lanthanide Luminescence. J. Phys. Chem. B 2002, 106, 6966-6972. [CrossRef]

35. Wang, Y.; Xin, X.; Li, W.; Jia, C.; Wang, L.; Shen, J.; Xu, G.-Y. Studies on the gel behavior and luminescence properties of biological surfactant sodium deoxycholate/rare-earth salts mixed systems. J. Colloid Interface Sci. 2014, 431, 82-89. [CrossRef] [PubMed]

36. Dong, F.; Wang, J.; Wang, Y.; Ren, S. Synthesis and humidity controlling properties of halloysite/poly(sodium acrylate-acrylamide) composite. J. Mater. Chem. 2012, 22, 11093. [CrossRef]

37. Adachi, T.; Shirotani, I.; Hayashi, J.; Shimomura, O. Phase transitions of lanthanide monophosphides with $\mathrm{NaCl}$-type structure at high pressures. Phys. Lett. A 1998, 250, 389-393. [CrossRef]

38. Jin, H.; Huang, Y.; Jian, J. Plate-like $\mathrm{Cr}_{2} \mathrm{O}_{3}$ for highly selective sensing of nitric oxide. Sens. Actuators B Chem. 2015, 206, 107-110. [CrossRef]

39. Zhang, F.; Wang, Z.; Chu, T.; Li, W.; Yang, Y. A facile fabrication of electrodeposited luminescent MOF thin film for selective and recyclable sensing nitroaromatic explosives. Analyst 2016, 141, 4502-4510. [CrossRef]

40. Aulsebrook, M.L.; Graham, A.P.B.; Grace, M.R.; Tuck, K.L. Lanthanide complexes for luminescence-based sensing of low molecular weight analytes. Coord. Chem. Rev. 2018, 375, 191-220. [CrossRef]

41. Hao, Z.; Song, X.; Zhu, M.; Meng, X.; Zhao, S.; Su, S.; Yang, W.; Song, S.; Zhang, H. One-dimensional channel-structured Eu-MOF for sensing small organic molecules and $\mathrm{Cu}^{2+}$ ion. J. Mater. Chem. A 2013, 1, 11043. [CrossRef]

42. Hao, Z.; Yang, G.; Song, X.; Zhu, M.; Meng, X.; Zhao, S.; Song, S.; Zhang, H. A europium(iii) based metal-organic framework: Bifunctional properties related to sensing and electronic conductivity. J. Mater. Chem. A 2014, 2, 237-244. [CrossRef]

43. Xiao, Y.; Cui, Y.; Zheng, Q.; Xiang, S. A microporous luminescent metal-organic framework for highly selective and sensitive sensing of $\mathrm{Cu}^{2+}$ in aqueous solution. Chem Comm 2010, 56, 5503-5505. [CrossRef] [PubMed]

44. Su, R.; Gao, J.; Deng, S.; Zhang, R.; Zheng, Y. Dual-target optical sensors assembled by lanthanide complex incorporated sol-gel-derived polymeric films. J. Sol. Gel. Sci. Technol. 2016, 78, 606-612. [CrossRef]

45. Bogale, R.F.; Ye, J.; Sun, Y.; Sun, T.; Zhang, S.; Rauf, A.; Hang, C.; Tian, P.; Ning, G. Highly selective and sensitive detection of metal ions and nitroaromatic compounds by an anionic europium(III) coordination polymer. Dalton Trans. 2016, 45, 11137-11144. [CrossRef]

46. Bogale, R.F.; Chen, Y.; Ye, J.; Zhang, S.; Li, Y.; Liu, X.; Zheng, T.; Rauf, A.; Ning, G. A terbium(III)-based coordination polymer for selective and sensitive sensing of nitroaromatics and ferric ion: Synthesis, crystal structure and photoluminescence properties. New J. Chem. 2017, 41, 12713-12720. [CrossRef]

47. Liu, W.; Wang, Y.; Song, L.; Silver, M.A.; Xie, J.; Zhang, L.; Chen, L.; Diwu, J.; Chai, Z.; Wang, S. Efficient and selective sensing of $\mathrm{Cu}^{2+}$ and $\mathrm{UO}_{2}{ }^{2+}$ by a europium metal-organic framework. Talanta 2019, 196, 515-522. [CrossRef]

48. Tan, H.; Zhang, Y.; Chen, Y. Detection of mercury ions $\left(\mathrm{Hg}^{2+}\right)$ in urine using a terbium chelate fluorescent probe. Sens. Actuators B Chem. 2011, 156, 120-125. [CrossRef]

49. Chen, B.; Wang, L.; Xiao, Y.; Fronczek, F.R.; Xue, M.; Cui, Y.; Qian, G. A Luminescent Metal-Organic Framework with Lewis Basic Pyridyl Sites for the Sensing of Metal Ions. Angew. Chem. Int. Ed. 2009, 48, 500-503. [CrossRef]

50. Du, P.-Y.; Gu, W.; Liu, X. Multifunctional Three-Dimensional Europium Metal-Organic Framework for Luminescence Sensing of Benzaldehyde and $\mathrm{Cu}^{2+}$ and Selective Capture of Dye Molecules. Inorg. Chem. 2016, 55, 7826-7828. [CrossRef]

51. Sun, Z.; Li, H.; Sun, G.; Guo, J.; Ma, Y.; Li, L. Design and construction of lanthanide metal-organic frameworks through mixed-ligand strategy: Sensing property of acetone and $\mathrm{Cu}^{2+}$. Inorg. Chim. Acta 2018, 469, 51-56. [CrossRef]

52. Wang, Z.; Liu, H.; Wang, S.; Rao, Z.; Yang, Y. A luminescent Terbium-Succinate MOF thin film fabricated by electrodeposition for sensing of $\mathrm{Cu}^{2+}$ in aqueous environment. Sens. Actuators B Chem. 2015, 220, 779-787. [CrossRef]

(C) 2020 by the authors. Licensee MDPI, Basel, Switzerland. This article is an open access article distributed under the terms and conditions of the Creative Commons Attribution (CC BY) license (http://creativecommons.org/licenses/by/4.0/). 